\title{
ENSINO FUNDAMENTAL DE NOVE ANOS E A INSERÇÃO DE CRIANÇAS DE SEIS ANOS NA ESCOLARIZAÇÃO OBRIGATÓRIA NO DISTRITO FEDERAL: ESTUDO DE CASO
}

\author{
Angélica Guedes Dantas* \\ Diva Maria M. A. Maciel*
}

\begin{abstract}
RESUMO: Este artigo traz uma reflexão sobre o processo de consolidação do ensino fundamental de nove anos na rede pública de ensino do Distrito Federal (DF) e põe em questão as peculiaridades da inserção de crianças de seis anos de idade nesse novo ambiente, a partir da ação docente observada no contexto de pesquisa. Constam da pesquisa uma microetnografia das salas de aula, a imersão no cotidiano escolar das classes participantes e entrevistas com as professoras. Participaram do estudo alunos e professoras de duas classes de primeiro ano de duas escolas públicas do Distrito Federal, de naturezas distintas. Os resultados analisados e discutidos a partir das orientações presentes nos documentos veiculados pelo Ministério da Educação sobre a temática são apresentados, tendo como foco a percepção dos professores sobre os meandros que permeiam a ampliação do ensino fundamental no DF.
\end{abstract}

Palavras-chave: Implantação de política pública. Ensino fundamental de nove anos. Inserção de crianças de seis anos. Atuação e formação docente.

* Mestranda em Psicologia pelo Instituto de Psicologia da Universidade de Brasília (UnB). E-mail: angelicagd@unb.br

** Doutora em Psicologia e professora do Programa de Pós-Graduação em Processos de Desenvolvimento Humano e Saúde, do Instituto de Psicologia da UnB. E-mail: diva@unb.br 
Ensino fundamental de nove anos e a inserção de crianças de seis anos...

NINE YEARS LONG ELEMENTARY SCHOOL AND THE INTEGRATION OF SIX-YEAR-OLD CHILDREN IN THE COMPULSORY SCHOOLING OF THE DISTRITO FEDERAL: A CASE STUDY

ABSTRACT: This paper presents a reflection on the process consolidating the nine years long elementary school in the public schooling system of the Distrito Federal. It specifically focuses on the integration of six-year-old children at this education level and on the teaching performance observed in the research context. It includes a classroom micro-ethnographic study, immersion in the school daily life of first graders and interviews with their teachers. It was conducted in two different public schools of the Distrito Federal. It presents the results obtained from the analysis and discussion of documents issued by the Ministerio da Educação with a special focus on the teachers' perception of the intricacies constituting the expansion of elementary school in the Distrito Federal.

Key words: Public policy implementation. Nine years long basic education. Integration of six-year-old children. Teachers' training activities.

\section{O ensino fundamental de nove anos}

D

e acordo com publicações ${ }^{1}$ do Ministério da Educação (MEC) o ensino fundamental (EF) de nove anos é um movimento mundial e, mesmo na América do Sul, são vários os países que o adotam. Essas publicações explicitam que, no Brasil, a determinação legal de implantar progressivamente o EF de nove anos, com a inclusão das crianças de seis anos de idade, tem duas intenções: oferecer maiores oportunidades de aprendizagem no período de escolarização obrigatória e assegurar que, ingressando mais cedo no sistema de ensino, as crianças prossigam nos estudos, alcançando maior nível de escolaridade.

Como está descrito no documento "Ensino Fundamental de Nove Anos - Orientações para a Inclusão da Criança de Seis Anos de Idade”, o MEC vem envidando efetivos esforços na ampliação do ensino fundamental para nove anos de duração, considerando a universalização do acesso a essa etapa de ensino e, ainda, a necessidade de o Brasil aumentar a duração da escolaridade obrigatória. A aprovação da Lei n. 11.274/ 2006, de 6 de fevereiro de 2006, possibilita a inclusão de um número maior de crianças no sistema educacional brasileiro, especialmente aquelas 
pertencentes aos setores populares, uma vez que as crianças de seis anos de idade das classes média e alta já se encontram, majoritariamente, incorporadas ao sistema de ensino - na pré-escola ou na primeira série do ensino fundamental.

A importância dessa decisão política relaciona-se ao fato de recentes pesquisas mostrarem que $81,7 \%$ das crianças de seis anos estão na escola, sendo que 38,9\% frequentam a educação infantil, $13,6 \%$ pertencem às classes de alfabetização e $29,6 \%$ estão no ensino fundamental, segundo dados do IBGE (2000). Sendo assim, a opção pela faixa etária dos seis aos 14 e não dos sete aos 15 para o ensino fundamental segue a tendência das famílias e dos sistemas de ensino de inserção progressiva das crianças de seis anos na rede escolar.

A inclusão, mediante a antecipação do acesso, é uma medida contextualizada nas políticas educacionais que pode levar a uma escolarização mais construtiva, isto porque a adoção de um ensino obrigatório de nove anos, iniciando aos seis anos de idade, pode contribuir para uma mudança na estrutura e na cultura escolar. No entanto, não se trata de transferir para as crianças de seis anos os conteúdos e atividades da tradicional primeira série, mas de conceber uma nova estrutura de organização dos conteúdos em um ensino fundamental de nove anos, considerando o perfil de seus alunos.

Diante disso, pretende-se que o ingresso dessas crianças no EF não se constitua apenas como uma medida meramente administrativa. É preciso atenção ao processo de desenvolvimento e aprendizagem delas, o que implica conhecimento e respeito às suas características etárias, sociais, psicológicas e cognitivas. Este é o momento para repensar todo o EF, tanto os cinco anos iniciais quanto os quatro finais, demandando providências para o atendimento das necessidades de recursos humanos - professores, gestores e demais profissionais de educação -, para lhes assegurar, entre outras condições, uma política de formação continuada em serviço, o direito ao tempo para o planejamento da prática pedagógica, assim como melhorias em suas carreiras. Além disso, os espaços educativos, os materiais didáticos, os mobiliários e os equipamentos precisam ser repensados para atender às crianças com essa nova faixa etária no $\mathrm{EF}$, bem como os alunos que já estavam nessa etapa de ensino, antes, com oito anos de duração.

O objetivo de um maior número de anos de ensino obrigatório é assegurar a todas as crianças um tempo mais longo de convívio escolar e 
Ensino fundamental de nove anos e a inserção de crianças de seis anos...

maiores oportunidades de aprender, o que significa uma possibilidade de qualificação do ensino, oportunidade para uma nova práxis dos educadores e, especialmente, para maior tempo para a aprendizagem da alfabetização e do letramento das crianças de seis anos de idade. É evidente que uma maior oportunidade de aprendizagem não depende apenas do aumento do tempo de permanência na escola, mas sim do emprego mais eficaz do tempo, por isso a importância de um trabalho pedagógico que assegure o estudo das diversas expressões e de todas as áreas do conhecimento, igualmente necessárias à formação do estudante do ensino fundamental.

Implantar um ensino fundamental, agora de nove anos, leva necessariamente a repensá-lo no seu conjunto. Sendo assim, é preciso que haja a reorganização pedagógica, de propostas, currículos e projetos político-pedagógicos, de modo que assegurem o pleno desenvolvimento das crianças em seus aspectos físico, psicológico, intelectual, social e cognitivo, tendo em vista alcançar os objetivos do EF sem restringir a aprendizagem das crianças de seis anos à exclusividade da alfabetização, mas sim ampliando as possibilidades de aprendizagem. Tudo isso, tendo a infância como eixo primordial e visando a reestruturação qualitativa dessa etapa de ensino.

Ao enfatizar o trabalho na criança de seis a dez anos, partindo do pressuposto de que elas trazem muitas histórias, muitos saberes, formas diversas de viver a infância, devemos, assim, recolocar no currículo o brincar como modo de ser e estar no mundo. Valorizando, também, a importância das diversas expressóes para o desenvolvimento da criança na escola e fortalecendo os tempos e espaços para o movimento, a dança, a música, a arte. Afinal, esse ser humano precisa vivenciar, sentir, perceber a essência de cada uma das expressóes que o tornam ainda mais humano.

\section{Discussões no campo teórico}

Sobre a temática em questão, encontramos, no campo teórico, duas vertentes que têm se debruçado sobre o assunto e publicado artigos. Há, claramente, os que são contrários à política de ampliação do EF e aqueles que questionam a aplicação, de fato, da medida no âmbito das escolas. Saveli (2008), por exemplo, discute a ampliação do EF de oito para nove anos como uma política de inclusão social, em que o 
Estado assume a garantia de acesso à escolaridade obrigatória e gratuita a todas as crianças na faixa etária de seis anos.

Para a autora, a inclusão dessas crianças na escolaridade obrigatória resgata um direito de cidadania, uma vez que permite a uma parcela maior da população se beneficiar de um direito que antes era de poucos. Por outro lado, salienta a exigência de tratamento político, administrativo e pedagógico para a consecução dos objetivos da proposta. Quais sejam: no nível político, aumenta-se o número de crianças incluídas no sistema educacional; no administrativo, exige-se das secretarias de Educação investimentos na formação de professores e na organização e adequação dos espaços físicos, materiais e pedagógicos; já no aspecto pedagógico, exige-se das escolas a reorganização de projetos pedagógicos que assegurem o pleno desenvolvimento dessas crianças. Com relação a isso, Kramer (2007) esclarece ser necessário garantir às crianças de seis anos o atendimento às suas necessidades de aprender e de brincar, o que não vale apenas para as crianças nesta faixa etária, mas para todos aquelas dos anos iniciais do $\mathrm{EF}$.

Gorni (2007), em seu trabalho, constatou que muito pouco se sabe acerca da proposta de implantação do ensino fundamental de 9 anos e que pairam, ainda, muitas dúvidas e preocupações sobre se a proposta não consiste somente em mais uma mudança política e estrutural. Para a autora, parece ficar evidente a precocidade da implantação de forma ampla e generalizada, antes de garantidas as condições de preparação das escolas e professores. Ela ressalta que a proposta em questão, a exemplo do que também já ocorreu com outras que a antecederam, tanto pode melhorar, como não alterar e até mesmo piorar o desempenho do sistema educacional, caso não receba o tratamento adequado em sua implementação. Além disso, segundo ela, a tendência é que apenas se antecipe em um ano a idade de ingresso no EF, o que poderia significar a supressão de uma etapa de trabalho importante, antes realizada no âmbito da educação infantil. Finalizando, Gorni (2007) afirma não observar uma ação planejada, organizada e sistemática de assessoramento às escolas na implantação do EF ampliado, uma vez que, no âmbito das escolas, predominou a preocupação com a possibilidade de ocorrer apenas a antecipação da alfabetização.

Dietrich e Peres (2007), em estudo acerca da implantação do EF ampliado no estado do Rio Grande do Sul, destacam que a política 
Ensino fundamental de nove anos e a inserção de crianças de seis anos...

poderá ser um tempo-espaço de construção de uma nova cultura escolar, onde se pode pensar a implantação do EF de nove anos, em nível nacional, como um espaço-tempo de mudar a escola, de modo que, cada vez mais, as crianças e os professores se assumam como responsáveis pelos projetos político-pedagógicos das escolas e por seus processos de ensinoaprendizagem. Segundo as autoras, uma nova cultura escolar não depende da "boa vontade" dos professores e professoras que estão nas salas de aula. Ela está profundamente articulada a questóes mais amplas como, por exemplo, a política salarial, as condiçóes de trabalho e, especialmente, a possibilidade de formação dos docentes.

Dessa forma, como salientam as autoras, a obrigatoriedade da matrícula das crianças com seis anos no EF de nove anos, instituída no Brasil com a Lei n. 11.274, não pode estar à margem de um amplo e irrestrito debate sobre os rumos do EF em seu conjunto. Assim, segundo elas, na ampliação do EF para nove anos, o trabalho de acompanhamento deverá estender-se por alguns anos para que, efetivamente, seja possível avaliar seu impacto no campo educacional, além de prever um conjunto de ações, de atores e de instituiçóes que possam efetiva e colaborativamente construir propostas e projetos coletivos para a alfabetização de crianças com seis anos, em específico, e para todo o EF, em geral.

\section{O ensino fundamental de nove anos do Distrito Federal}

A Secretaria de Estado de Educação do Distrito Federal (SEE-DF), como aponta Villas Boas (2006), iniciou a implantação do EF de nove anos em 2005 com a incorporação das crianças de seis anos de idade. Para tanto, criou o Bloco Inicial de Alfabetização (BIA). Neste mesmo ano, o DF iniciou o atendimento às crianças de seis anos, no EF, em apenas algumas regionais de ensino, de forma ainda experimental. Vários projetos foram conduzidos, especialmente em Ceilândia, região administrativa do Distrito, com o intuito de diminuir o fracasso escolar. Sabe-se, porém, que o DF já vinha atendendo essas crianças no terceiro período da educação infantil, de forma ainda não universalizada, e a consolidação do processo de atendimento das crianças no EF se deu de fato no ano de 2008.

A resposta do DF à necessidade de reestruturação do EF tem a intenção de promover a progressão continuada do processo de aprendizagem, assegurando aos alunos a partir de seis anos, além de um tempo 
maior de escolaridade, condições de permanência no sistema público de ensino. Vislumbrando a aquisição da alfabetização e letramento na perspectiva da ludicidade e do desenvolvimento global, o BIA compreende o atendimento às crianças de seis, sete e oito anos, enturmadas pelo critério de idade e possibilitando a organização de um tempo maior e mais flexível para o desenvolvimento das competências que a criança precisa possuir (Governo do Distrito Federal, 2005).

Nesta perspectiva, como aponta Pereira (2008), a formação continuada dos professores que atuam no BIA é preconizada como um dos princípios metodológicos para seu sucesso. Acredita-se, assim, que é por meio da formação que o professor tem a possibilidade de construir sua autonomia pedagógica.

Dado esse cenário e diante do levantamento teórico realizado, constatamos a lacuna existente de trabalhos empíricos que, usando os diversos atores do processo educacional, retratem o quadro atual de implementação do processo de ampliação do EF e da inserção das crianças de seis anos e, além disso, levantem os direcionamentos mais condizentes para o sucesso da proposta, para a ressignificação deste nível de ensino, como está proposto nas orientações do MEC, e para a atuação e formação do docente.

\section{A pesquisa}

A proposta aqui é colocar em questão as peculiaridades deste novo ensino fundamental e contribuir para otimização da ação docente e para a efetivação da medida junto às instituiçôoes escolares. Objetivando contribuir para a compreensão do processo de ampliação do EF no Distrito Federal e da inserção das crianças de seis anos nesse nível de ensino, constou da pesquisa a imersão no cotidiano de classes de primeiro ano de duas escolas públicas do Distrito, vinculadas à regional de ensino do Plano Piloto. Participaram do estudo alunos e professoras das classes referidas. Na primeira escola, um jardim de infância que atende crianças entre quatro e seis anos de idade e oferece àquelas últimas o primeiro ano do EF, a turma participante da pesquisa foi indicada pela direção e conta com 25 alunos. Na segunda instituição, uma escola-classe que atende crianças a partir dos seis anos de idade e tem alunos com até 14 anos, a turma escolhida conta com 14 alunos, na mesma faixa etária da primeira. Ambas as turmas são do turno vespertino. 
Ensino fundamental de nove anos e a inserção de crianças de seis anos...

Dado o contexto da pesquisa, foi conduzida uma microetnografia das salas de aula, com base em referencial metodológico sobre a pesquisa etnográfica (Erickson, 1984, 1989, 1990; Fonseca, 1999; Fonseca \& Brittes, 2006; González Rey, 2005; Gonzáles Rey \& Martinez, 1989; Mehan, 1992), em que o pesquisador imbricado no constante exercício de reflexão considera não só o que os sujeitos falam ou fazem, mas como o fazem - o sentido da fala/ ação - e, ainda, o nível de envolvimento deles nos processos relacionais.

Assim, entrevistas foram realizadas com as professoras, sequências interativas foram registradas em diário de bordo e em imagens videográficas e analisadas a partir de categorias elaboradas com base no documento "Ensino Fundamental de Nove anos - Orientaçōes para a Inclusão de Crianças de Seis Anos de Idade" e nas particularidades encontradas no contexto da pesquisa.

A opção, no estudo original, foi por trabalhar com quatro categorias, quais sejam: (1) Reorganização pedagógica; (2) A infância como eixo primordial; (3) A importância das diversas expressões do desenvolvimento humano e (4) Letramento e alfabetização - e trazer os resultados sobre dois enfoques: a partir de trechos de falas das professoras retirados das entrevistas e de sequências interativas registradas no diário de bordo e nas filmagens.

Neste artigo, porém, optamos por centrar a discussão nos dados oriundos das entrevistas e em algumas observações feitas quando da imersão nas classes, o que se justifica pela urgência de tratarmos das percepçōes dos professores sobre os meandros que permeiam a ampliação do EF no Distrito Federal. Assim, partindo das questōes norteadoras, apresentaremos a seguir as principais constatações do estudo:

- Quais as estratégias em curso implementadas por professores e gestores educacionais para o melhor dimensionamento da prática pedagógica com relação às propostas, currículos, projetos político-pedagógicos, concepções de avaliação etc.?

- Partindo da infância como eixo primordial, de que forma escolas e professores têm contribuído para a revalorização do brincar em sala de aula e assegurado espaço privilegiado para discussão e implementação de projetos sobre a temática?

- Em que medida o processo de ensino-aprendizagem desenvolvido nas escolas estudadas tem favorecido o diálogo com o ser 
humano em todas suas dimensões, ou seja, tem garantido tempos e espaços para atividades que envolvam o movimento, a dança, a música, as artes em geral, e de que forma isso tem acontecido?

- Quais as relações estabelecidas entre as crianças e o mundo da escrita, os investimentos feitos na formação de leitores, o papel desempenhado pelos professores nesse processo? E, ainda: há, erroneamente, maior favorecimento de conteúdos da alfabetização em detrimento das demais áreas do conhecimento?

\section{Principais constataçôes}

Um dos primeiros insights sobre o processo, após a imersão da pesquisadora no contexto das duas escolas, foi a problemática da dissociação da proposta em dois ambientes distintos - jardins de infância (educação infantil) e escolas-classe (ensino fundamental) -, haja vista a impossibilidade de atenção à enorme demanda de crianças para entrada no primeiro ano. $\mathrm{O}$ que parece uma resposta simplista para a equação escassez de espaço físico versus demanda reprimida se desvela já como um empecilho à consecução dos objetivos de reestruturação do EF no Distrito Federal. Em que medida pode-se cogitar uma estruturação do EF num contexto onde não está claro o que é a educação infantil e o que significa os primeiros anos do EF?

Não temos a intenção aqui de classificar ou rotular os dois níveis de ensino, tampouco de apontar os melhores ou piores no que diz respeito à atenção às crianças de seis anos de idade. O fato é que essa confusão em nível administrativo e pedagógico é o pano de fundo do processo de universalização do EF ampliado no Distrito Federal. Será mesmo possível falarmos em universalização? Há equidade? Será que está claro para gestores e professores o que é a proposta de aumento dos anos de escolaridade obrigatória? Como os diversos atores do processo educacional têm reagido às mudanças?

Dado o pano de fundo do processo de inserção das crianças de seis anos no EF, trataremos agora das percepções das professoras que participaram da pesquisa, cujos perfis serão descritos a seguir.

Ana (nome fictício, professora do jardim de infância) tem 39 anos de idade, concluiu o curso de Magistério, é formada em Pedagogia pela 
Ensino fundamental de nove anos e a inserção de crianças de seis anos...

Universidade de Brasília (UnB), fez vários cursos de formação na área de educação infantil e, atualmente, está cursando especialização oferecida, por intermédio da UnB, para os professores da Secretária de Educação do DF. Ana é uma professora já experiente, conta com 22 anos de serviços prestados à SEE-DF, dos quais os três últimos são na escola alvo da pesquisa.

Cristina (nome fictício, professora da escola classe) tem 23 anos de idade, é recém-formada em Pedagogia pela UnB e está em contrato temporário. Tem pouca experiência, apenas aquelas dos estágios supervisionados e de projetos desenvolvidos na Universidade. Ela relata afeição pelas crianças pequenas e esclarece sua opção pelas "mais novinhas" quando da chegada na escola.

Quando questionada sobre o primeiro ano do EF, série em que atua, Ana se mostrou, como apontado no primeiro insight, um tanto quanto perdida. Disse que, a partir de agora, o que era o terceiro período da educação infantil até o ano anterior passou a ser a primeira etapa do ensino fundamental. Contudo, ao se referir à série em questão, por várias vezes fez confusão entre a educação infantil e o ensino fundamental. Num trecho de sua fala, destacou: "no primeiro ano, como educação infantil, as crianças têm o desenvolvimento próprio”. Ela salienta, também, não ter recebido turmas de primeira série (nomenclatura utilizada anteriormente) e sim ter continuado com turmas de alunos de seis anos, que agora fariam parte do EF.

Ao ser questionada sobre a especificidade desse novo nível e, particularmente, sobre o primeiro ano, disse saber da existência de diferenciação na proposta curricular do BIA, no contexto do EF de nove anos, mas destacou estar ainda muito confusa sobre o que fazer e como atuar. $\mathrm{Na}$ sua fala, essa preocupação fica evidente:

As informações não chegaram bem. Apesar da gente estar fazendo um curso, oferecido pela Secretaria para todos os professores que estão com primeiro ano, para dar encaminhamento sobre a proposta, mas ainda não tivemos acesso a informaçôes que pudessem ajudar. Estamos trabalhando da mesma maneira que estávamos e aí, conforme recebemos alguma orientação, vamos adequando ao que é esperado.

Além disso, Ana relata a ausência de suporte na própria escola, esclarecendo que estão sem supervisão escolar e que a coordenadora não tem 
nenhuma experiência. Com relação ao curso oferecido, salienta: "o andamento está muito lento, já estamos quase no meio do ano e as informações são muito desencontradas, cada um chega com uma informação, cada hora é uma coisa diferente".

A narrativa de Ana demonstra algumas das problemáticas que permeiam o processo de implantação do EF ampliado no Distrito Federal. Fica evidente o despreparo dos professores para atuação segundo a proposta do MEC e, também, a falta de posicionamento da escola como instituição para propor estratégias de atenção às crianças de seis anos, lhes garantido tratamento diferenciado do oferecido na educação infantil, sem, contudo, esquecer as particularidades próprias da faixa etária. A professora nos diz estar fazendo o mesmo que fazia antes com turmas do terceiro período da educação infantil e que as adequações estão ocorrendo no percurso. É compreensível sua atitude, mas devemos estar atentos para a urgência de garantir aos professores, entre outras condiçôes, uma política de formação em serviço, o direito ao tempo para planejamento da prática pedagógica e, ainda, melhorias em suas carreiras. Além disso, é preciso reconhecer este momento como o de rever currículos, conteúdos e práticas, com vistas a não conceber a criança de seis anos de idade com um sujeito a quem faltam conteúdos da educação infantil ou que será preparado para os anos seguintes do EF.

Cristina, quando questionada sobre a inserção de crianças de seis anos no EF, respondeu: "acho que essa obrigatoriedade acarreta mais responsabilidade para o professor enquanto profissional, mas para as crianças não... elas não têm nada a ver com isso, elas estão lá na escola, somos nós que devemos ter consciência das suas necessidades e peculiaridades". Em sua fala, Cristina enaltece sua preocupação com a pouca idade dos alunos. Segundo ela: "são crianças de cinco/seis anos, a maioria tem cinco mesmo, são muito pequenas ainda". Por isso, salienta a importância de enfatizar a afetividade, de reservar momentos para brincadeiras e de tratar de noções de responsabilidade, higiene e cuidado; além disso, resgata a difícil realidade da escola pública: "são crianças que precisam brincar, que precisam ser cuidadas com carinho, mas no contexto da escola pública é muito difícil, é tudo muito desprotegido, elas são obrigadas a crescer mais cedo, a ter independência maior".

Sobre a continuidade da oferta do primeiro ano no contexto dos jardins de infância, Ana disse: “(...) a intenção, futuramente, é passar 
Ensino fundamental de nove anos e a inserção de crianças de seis anos...

essas turmas para as escolas classe". Segundo ela, com o terceiro ano passando a ser ensino fundamental, recai sobre eles - professores - uma obrigação legal/formal de alfabetizar. Ela comenta: "essa criança estava chegando ao final muito defasada e eles acham que o problema tá aqui, mas na verdade essas crianças eram alfabetizadas, quer dizer, agora tem obrigação, antes não tinha, mas o trabalho era o mesmo".

Assim como Ana, a professora do jardim de infância, Cristina, mostrou-se preocupada com a obrigação de alfabetizar: "os alunos precisam ser alfabetizados, mas essa responsabilidade não pode recair sobre eles. Eu, como professora, absorvo toda a responsabilidade, quando eles são avaliados a responsabilidade é do professor, do profissional”. Sobre essa questão, ela falou, também, do sentimento de insegurança com relação à alfabetização de seus alunos e destacou que experiências no terceiro período da educação infantil e na extinta primeira série lhe dariam mais segurança para atuação em sala de aula.

Levada a pensar sobre sua atuação, caso estivesse lecionando num jardim de infância, Cristina destacou: "lá seria um trabalho mais voltado para o cuidado, de recreação e socialização dos alunos, essa obrigação de ler e escrever não seria tão grande, afinal, apesar de serem estimulados e muitos até terem fortes noções de leitura e escrita, isso ainda não é obrigatório".

Os relatos das professoras demonstram, mais uma vez, a não compreensão da proposta de ampliação do EF. Sabe-se que a medida representa uma alternativa para frear a evasão e o fracasso escolares, bem como a defasagem idade/série. Porém, seu objetivo primordial é garantir às crianças um tempo maior para a aprendizagem, assegurando, por meio do ingresso mais cedo no sistema de ensino, que elas prossigam nos estudos.

Com relação à alfabetização e letramento, percebe-se certa confusão no âmbito das escolas. Por isso, cabe ressaltar que a ideia é, parafraseando Leal, Albuquerque e Morais (2007a), que a escola desde o primeiro ano se preocupe com o desenvolvimento dos conhecimentos relativos à aprendizagem da escrita alfabética, assim como daqueles ligados ao uso e à produção da linguagem escrita. Dessa forma, a escola deve assegurar a todos os estudantes a vivência de práticas reais de leitura e produção de textos diversificados, promovendo atividades que envolvam toda a diversidade textual e levem os estudantes a construir conhecimento sobre o uso da leitura/escrita na sociedade. 
Ainda sobre esse aspecto, temos dados oriundos das observações em sala de aula. No jardim de infância, Ana tem empreendido estratégias interessantes de alfabetização/letramento com crianças do primeiro ano. Por meio da leitura de clássicos da literatura infantil nacional, de autoria de Machado de Assis, Cecília Meireles e Ziraldo, por exemplo, tem ampliado o repertório de leitura/escrita das crianças, motivado a inserção no universo letrado e introduzido conteúdos de base para a consecução da alfabetização. Ao ler para o grupo, Ana possibilita aos estudantes observarem o escrito e o ilustrado, o que favorece a construção de ideias cada vez mais elaboradas sobre o que é ler e escrever e a apropriação de estratégias de leitura típicas de um leitor já experiente.

Já na escola-classe, Cristina, até por conta de sua inexperiência, deixa a desejar no quesito alfabetização. Muito preocupada com as cobranças da direção da escola e sem elementos para desenvolver um trabalho qualitativamente melhor, não faz uso de estratégias eficazes. Percebe-se na sala de aula vários incentivos textuais como alfabetos coloridos, calendários, recortes de falas e texto e, até mesmo, uma minibiblioteca. Porém, estes elementos não são frequentemente utilizados pela professora. Num episódio específico, por exemplo, algumas crianças brincam com o alfabeto móvel de EVA, mas a professora não sabe o que fazer para explorar o potencial ali adormecido. Em turno de fala durante a entrevista, Cristina rechaça as constatações anteriormente descritas. Questionada sobre cobranças dos pais e da direção da escola, ela pontua:

(...) recebo muitas cobranças da direção, houve um momento marcante para mim, a minha frustração depois do teste da psicogênese na escola, eu achei até injusto porque eu achei que tinha trabalhado outras coisas e, de repente, meu trabalho foi desmerecido. O que conta é isso, se os alunos iniciam o ano pré-silábico a esperança é que eles terminem silábicos ou silábicos alfabéticos, se isso não for alcançado...

Seu discurso evidencia mais um equívoco na interpretação da proposta e, também, a falta de disposição da escola para o trabalho coletivo. Como salientam Leal, Albuquerque e Morais (2007b), as práticas de avaliação desenvolvidas na escola têm se constituído em práticas de exclusão. A exemplo do ocorrido na escola pesquisada, avalia-se para medir a aprendizagem dos estudantes e classificá-los em aptos ou não aptos.

Nessa ótica, faz-se necessário reconhecer esta oportunidade como a de rever concepções e práticas de avaliação. Tornam-se urgentes a revisão 
Ensino fundamental de nove anos e a inserção de crianças de seis anos...

e a mudança de determinadas concepções de avaliação que se traduzem e se perpetuam em práticas discriminatórias e redutoras das possibilidades de aprender. É importante refletirmos sobre uma escola disposta a elaborar outros procedimentos e instrumentos, além da prova bimestral e do exercício de verificação, uma escola disposta a entender que o ser humano é singular na forma, na quantidade do aprender e em demonstrar suas aprendizagens. Como explicitado nas orientações do MEC, é o momento de por em prática uma avaliação ética e democrática.

Outro problema relatado por Cristina diz respeito à precocidade do contato com adolescentes e pré-adolescentes. Segundo a professora: "é precoce, é complicado colocar uma criança de cinco anos para estudar junto com um adolescente, 12, 13, 14 anos do quinto ano, é precoce”. Essa constatação faz um alerta para que professores e gestores se sensibilizem com as especificidades, as potencialidades, os saberes, os limites, as possibilidades das crianças e adolescentes diante do desafio de uma formação voltada para a cidadania. Faz-se necessário definir um perfil de saída de cada etapa de ensino e assegurar esforços para compreender os processos de construção de conhecimentos das crianças e adolescentes. Assim, como aponta Nery (2007), é fundamental que os professores e a equipe pedagógica reflitam sobre o que deve ser priorizado em cada etapa de ensino e planejem como organizar o processo de aprendizagem das crianças e adolescentes.

Essa questão nos remete para a importância da reafirmação de um trabalho pedagógico que assegure o estudo das diversas expressões do desenvolvimento humano e de todas as áreas do conhecimento, igualmente necessárias à formação do estudante do ensino fundamental. Para favorecer a aprendizagem de crianças e adolescentes, precisamos dialogar com o ser humano, em todas as suas dimensóes, garantindo assim tempos e espaços para o movimento, a dança, a música, a arte. Afinal, como salientado nas orientaçóes do MEC, esse ser humano, que carrega a leveza da infância ou a inquietude da adolescência, precisa vivenciar, sentir, perceber a essência de cada uma das expressões que o tornam ainda mais humano.

No curso da pesquisa, conhecemos um projeto muito interessante de estimulação motora e ludicidade, desenvolvido no jardim de infância como parte integrante da ação de extensão promovida pela UnB: "Detecção de Potenciais para Desenvolver a Ginástica Artística de Alto Nível”. 
A ação visa, basicamente, selecionar crianças da pré-escola com aptidões específicas e características físicas próprias da modalidade. No entanto, a forma como os monitores (alunos do curso de Educação Física) vêm lidando com as crianças envolvidas acaba por proporcionar a elas uma grande chance de desenvolver habilidades motoras e de participar de um grupo social saudável, estimulador e educativo, que é o esportivo. Trechos das filmagens e o relato da professora evidenciam o prazer vivenciado pelas crianças nesta atividade. Ana, durante a entrevista, comentou: "é um trabalho superimportante para as crianças, que faz a diferença; através da brincadeira e se divertindo elas tomam mais conhecimento do próprio corpo e do seu espaço".

Sabemos da validade e importância de projetos como esse no âmbito das escolas. Por isso, foi uma pena constatar que nada semelhante está sendo desenvolvido na escola-classe pesquisada. Fica evidente e marcada pela descontinuidade a transição da educação infantil para o ensino fundamental. E, sob nosso ponto de vista, a esse respeito, estariam sim sendo privilegiadas as crianças alojadas no jardim de infância, mesmo frequentando o primeiro ano do ensino fundamental. Assim, faz-se necessário garantir, mesmo no período de transição entre as duas estruturas, propostas curriculares que assegurem as mais diversas aprendizagens para o sucesso tanto das crianças e adolescentes, quanto da escola enquanto instituição.

Para finalizar, gostaríamos de enfatizar a importância do trato afetivo, com responsabilidade, frente aos alunos de ambos os contextos. É preciso que estejamos atentos e preparados para criar espaços de trocas e aprendizagens significativas, onde todos possam viver a experiência de um ensino rico em afetividade e descobertas. Assim, cabe à escola oferecer um ambiente escolar acolhedor, onde a infância (e também a adolescência) possa ser vivida em toda sua plenitude. Para reforça essa necessidade, recorremos a Goulart (2007), que salienta: se não conseguirmos desenvolver relaçóes de confiança e afeto com os alunos, dificilmente construiremos uma relação de ensino-aprendizagem positiva.

\section{Considerações finais}

Apesar de, em sua proposta, o BIA destinar três anos para o processo de alfabetização, é evidente o sentimento de obrigação carregado 
Ensino fundamental de nove anos e a inserção de crianças de seis anos...

pelos professores. Possivelmente, o peso dessa responsabilidade seja oriundo de uma interpretação errônea da proposta e da desvirtualização de seus fundamentos.

Educação infantil e ensino fundamental são frequentemente separados. Porém, como observa Kramer (2007), do ponto de vista da criança não há fragmentação. Os adultos é que, muitas vezes, opõem os dois níveis, deixando de lado o que seria capaz de articulá-los. Tudo isso implica ver o pedagógico na sua dimensão cultural, como conhecimento, arte e vida, e não apenas como algo instrucional.

O importante é que saibamos, independentemente do nível, ver, entender e lidar com as crianças como tal e não apenas como estudantes, considerando suas necessidades - a de aprender e de brincar. Dessa forma, o foco é garantirmos condições adequadas para recepcioná-las no ensino fundamental e para a ampliação do debate no interior de cada escola, o que implica a reorganização dos currículos, dos projetos político-pedagógicos e das propostas pedagógicas em geral. Assim, para concluir, retomamos a questão posta por Nascimento (2007, p. 28): "Quem sabe a entrada das crianças de seis anos no ensino fundamental não nos ajude a ver de forma diferente as crianças que já estavam em nossas salas de aula? Fica a sugestão!".

\section{Recebido em fevereiro de 2009 e aprovado em janeiro de 2010.}

\section{Nota}

1. Dentre os documentos orientadores elaborados pelo MEC sobre a temática, destacamos: "Orientações Gerais"; "Orientações para a Inclusão de Crianças de Seis Anos de Idade"; "Ensino Fundamental de Nove Anos - 10 Relatório" e "Ensino Fundamental de Nove Anos - 2o Relatório”.

\section{Referências}

BRASIL. Lei n. 9.394, de 20 de dezembro de 1996. Estabelece as diretrizes e bases da educação nacional. Diário Oficial da União, Brasília, DF, 23 de dezembro de 1996.

BRASIL. Lei n. 11.274, de 06 de fevereiro de 2006. Altera a redação dos arts. 29, 30, 32 e 87 da Lei 9.394, de 20 de dezembro de 1996, 
que estabelece as diretrizes e bases da educação nacional. Diário Oficial da União, Brasília, DF, 07 de fevereiro de 2006.

BRASIL. Ministério da Educação. Secretaria de Educação Básica. Ensino fundamental de nove anos: orientações gerais. Brasília, DF: MEC, 2004.

BRASIL. Ministério da Educação. Secretaria de Educação Básica. Ensino fundamental de nove anos: orientações para a inclusão da criança de seis anos de idade. Brasília, DF: MEC, 2007.

DIETRICH, M.D.; PERES, E.T. Ensino fundamental de nove anos em Pelotas, RS: o projeto piloto da Secretaria Estadual de Educação para alfabetização de crianças com seis anos. Programa Circuito Campeão do Instituto Ayrton Senna/SP, 2007.

DISTRITO FEDERAL (Governo). Orientaçôes gerais para o ensino fundamental de nove anos: bloco inicial de alfabetização. Brasília, DF: Secretaria de Estado de Educação, 2005.

ERICKSON, F. What makes school ethnography "Ethnographic"? Athropology and Education Quarterly, Washington, DC, v. 15, n. 1, p. 51-66, 1984.

ERICKSON, F. Métodos cualitativos de investigación sobre la enseñanza. In: Wittrock, M. (Org.). La investigación de la enseñanza. Barcelona: Paidos, 1989.

ERICKSON, F. Qualitative methods. In: LINN, R.L.; ERICKSON, F. (Org.). Research in teaching and learning. New York: American Educational Research Association, 1990. p. 75-194.

FONSECA, C.L.W. Quando cada caso não é um caso: pesquisa etnográfica e educação. Revista Brasileira de Educação, São Paulo, n. 10, p. 58-78, 1999.

FONSECA, C.L.W.; BRITTES, J. Etnografias da participação. Santa Cruz do Sul: EDUnisC, 2006.

GONZÁLES REY, F. Pesquisa qualitativa e subjetividade. São Paulo: Thompson, 2005. 
Ensino fundamental de nove anos e a inserção de crianças de seis anos...

GONZÁLEZ REY, F.; MARTINÉZ, A.M. La personalidad, su educación y desarollo. Havana: Pueblo y Educación, 1989.

GORNI, D.A.P. Ensino fundamental de nove anos: estamos preparados para implantá-lo? Ensaio: Avaliação, Políticas Públicas e Educação, Rio de Janeiro, v. 15, n. 54, p. 67-80, 2007.

GOULART, C. A organização do trabalho pedagógico: alfabetização e letramento como eixos orientadores. In: BRASIL. Ministério da Educação. Secretaria de Educação Básica. Ensino fundamental de nove anos: orientações para a inclusão de crianças de seis anos de idade. Brasília, DF: MEC, 2007. p. 85-96.

IBGE. Instituto Brasileiro de Geografia e Estatística. Censo Demográfico 2000. Rio de Janeiro: IBGE, 2000.

KRAMER, S. A infância e sua singularidade. In: BRASIL. Ministério da Educação. Secretaria de Educação Básica. Ensino fundamental de nove anos: orientações para a inclusão de crianças de seis anos de idade. Brasília, DF: MEC, 2007. p. 13-24.

LEAL, T.F.; ALBUQUERQUE, E.B.C.; MORAIS, A.G. Letramento e alfabetização: pensado a prática pedagógica. In: BRASIL. Ministério da Educação. Secretaria de Educação Básica. Ensino fundamental de nove anos: orientações para a inclusão de crianças de seis anos de idade. Brasília, DF: MEC, 2007a. p. 69-84.

LEAL, T.F.; ALBUQUERQUE, E.B.C.; MORAIS, A.G. Avaliação e aprendizagem na escola: a prática pedagógica como eixo de reflexão. In: BRASIL. Ministério da Educação. Secretaria de Educação Básica. Ensino fundamental de nove anos: orientações para a inclusão de crianças de seis anos de idade. Brasília, DF: MEC, 2007b. p. 97-108.

MEHAN, H. Understanding inequality in schools: the contribution of interpretative studies. Sociology of Education, Albany, v. 62, n. 1, p. 265-286, 1992.

NASCIMENTO, A.M. A infância na escola e na vida: uma relação fundamental. In: BRASIL. Ministério da Educação. Secretaria de Educação Básica. Ensino fundamental de nove anos: orientações para a inclusão de crianças de seis anos de idade. Brasília, DF: MEC, 2007. p. 85-96. 
NERY, A. Modalidades organizativas do trabalho pedagógico: uma possibilidade. In: BRASIL. Ministério de Educação. Secretaria de Educação Básica. Ensino fundamental de nove anos: orientações para a inclusão de crianças de seis anos de idade. Brasília, DF: MEC, 2007. p. 109-135.

PEREIRA, M.S. Avaliação no Bloco Inicial de Alfabetização: a realidade de uma escola no Distrito Federal. 2008. 182f. Dissertação (Mestrado) - Faculdade de Educação, Universidade de Brasília, Brasília, DF.

SAVELI, E.L. Ensino fundamental de nove anos: bases legais de sua implantação. Práxis Educativa, Ponta Grossa, v. 3, n. 1, p. 61-72, 2008.

VILLAS BOAS, B.M.F. Avaliação no Bloco Inicial de Alfabetização no Distrito Federal. In: REUNIÃO ANUAL DA ASSOCIAÇÃO NACIONAL DE PÓS-GRADUAÇÃO E PESQUISA EM EDUCAÇÃO, 29., 2006, Caxambu. Anais... Caxambú: anPEd, 2006. 